\title{
Impaired Head Direction Cell Representation in the Anterodorsal Thalamus after Lesions of the Retrosplenial Cortex
}

\author{
Benjamin J. Clark, Joshua P. Bassett, Sarah S. Wang, and Jeffrey S. Taube \\ Department of Psychological and Brain Sciences, Center for Cognitive Neuroscience, Dartmouth College, Hanover, New Hampshire 03755
}

The retrosplenial cortex (RSP), a brain region frequently linked to processes of spatial navigation, contains neurons that discharge as a function of a rat's head direction (HD). HD cells have been identified throughout the limbic system including the anterodorsal thalamus $(\mathrm{ADN})$ and postsubiculum $(\mathrm{PoS})$, both of which are reciprocally connected to the RSP. The functional relationship between HD cells in the RSP and those found in other limbic regions is presently unknown, but given the intimate connectivity between the RSP and regions such as the ADN and PoS, and the reported loss of spatial orientation in rodents and humans with RSP damage, it is likely that the RSP plays an important role in processing the limbic HD signal. To test this hypothesis, we produced neurotoxic or electrolytic lesions of the RSP and recorded HD cells in the ADN of female Long-Evans rats. HD cells remained present in the ADN after RSP lesions, but the stability of their preferred firing directions was significantly reduced even in the presence of a salient visual landmark. Subsequent tests revealed that lesions of the RSP moderately impaired landmark control over the cells' preferred firing directions, but spared the cells directional stability when animals were required to update their orientation using self-movement cues. Together, these results suggest that the RSP plays a prominent role in processing landmark information for accurate HD cell orientation and may explain the poor directional sense in humans that follows damage to the RSP.

\section{Introduction}

Converging evidence suggests that the retrosplenial cortex (RSP) contributes to the process of spatial navigation (Aggleton and Vann, 2004; Harker and Whishaw, 2004; Dean and Platt, 2006; Epstein, 2008; Pothuizen et al., 2008; Vann et al., 2009). Much of the evidence supporting this notion comes from studies in which RSP lesioned rats are tested in spatial tasks requiring the use of external allothetic information (e.g., visual landmarks) (Sutherland et al., 1988; Harker and Whishaw, 2002, 2004; Vann and Aggleton, 2004; Cain et al., 2006) or internally generated idiothetic cues (vestibular and motor) (Cooper et al., 2001; Whishaw et al., 2001). In general, RSP lesions impair performance in these tasks provided that the lesions are large, extending throughout the rostral-caudal extent of RSP (Vann et al., 2003; Vann and Aggleton, 2004). Navigational difficulties are also reported after the RSP is damaged by stroke in humans (Cammalleri et al., 1996; Takahashi et al., 1997; Aguirre and D'Esposito, 1999; Maguire, 2001; Greene et al., 2006; Osawa et al., 2008), and functional neuroimaging studies frequently demonstrate strong bilateral $\mathrm{RSP}$ activation in tasks involving spatial problem solving (Magu-

Received July 14, 2009; revised Feb. 25, 2010; accepted March 3, 2010.

This research was supported through National Institutes of Health Grant NS053907 (awarded to J.S.T.) and a postgraduate fellowship from the National Sciences and Engineering Research Council of Canada (awarded to B.J.C.). We thank Jennifer Rilling for technical assistance.

Correspondence should be addressed to Jeffrey S. Taube, Department of Psychological and Brain Sciences, Dartmouth College, Hanover, NH 03755. E-mail: jeffrey.taube@dartmouth.edu.

DOI:10.1523/JNEUROSCI.3380-09.2010

Copyright $\odot 2010$ the authors $\quad 0270-6474 / 10 / 305289-14 \$ 15.00 / 0$ ire, 2001; Wolbers and Büchel, 2005; Epstein et al., 2007; Iaria et al., 2007; Park and Chun, 2009).

A striking feature of the spatial deficits following RSP damage in humans is the report that patients suffer from what has been described as heading (or topographic) disorientation (Cammalleri et al., 1996; Aguirre and D'Esposito, 1999; Greene et al., 2006; Ino et al., 2007). These patients are generally unable to orient with respect to available environmental landmarks and set a course to where they want to go, even though they are capable of recognizing the landmarks and are capable of describing the intended destination. The reported loss of heading orientation is frequently linked to the fact that, in rats, the RSP contains a population of cells that discharge as a function of head direction (HD) (Chen et al., 1994; Cho and Sharp, 2001), but independent of location and ongoing behavior. Different HD cells have different preferred orientations, which collectively form a "neural compass" representing the animal's moment-to-moment orientation (Wiener and Taube, 2005; Taube, 2007). HD cells have been observed in an interconnected limbic circuit that includes the postsubiculum (PoS) (Taube et al., 1990a,b), anterodorsal thalamus (ADN) (Taube, 1995), and lateral mammillary nuclei (Blair et al., 1998; Stackman and Taube, 1998).

At present, the functional relationship between HD cells in the RSP and those found in other limbic regions is unclear. However, the strong reciprocal connections with regions such as the ADN and PoS (van Groen and Wyss, 1990, 1992, 2003; Jones and Witter, 2007), and the observed navigation impairments after RSP lesions suggests that the RSP might play an important role in HD signal processing. Thus, the present study addressed this gap in 
Table 1. Stereotaxic coordinates for RSP lesions

\begin{tabular}{lll}
\hline$A-P$ & $M-L$ & $D-V$ \\
\hline-3.1 & \pm 0.50 & -3.15 \\
-4.6 & \pm 0.80 & -3.15 \\
-6.1 & \pm 1.00 & -3.75 \\
-7.6 & \pm 1.35 & -3.25 \\
-9.0 & \pm 1.95 & -3.25 \\
\hline
\end{tabular}

$\overline{A-P, \text { Anterior-posterior; } M-L \text {, medial-lateral; D-V, dorsal-ventral (all measurements are derived from bregma in }}$ millimeters).

the literature by lesioning the RSP in rats and recording HD cell activity in the ADN. Here, we report that RSP lesions generally reduce the directional specificity of ADN HD cells and moderately impair their orientation in relation to landmarks, but leave idiothetic cue processing mostly intact. Collectively, these findings suggest a prominent role for the RSP in processing HD representations in the $\mathrm{ADN}$, and may explain the poor directional sense that often follows RSP damage.

\section{Materials and Methods}

\section{Subjects}

Subjects were 33 female Long-Evans rats, weighing 250-300 g at the beginning of testing. Rats were singly housed in Plexiglas cages and maintained on a $12 \mathrm{~h}$ light/dark cycle. Water was provided ad libitum while access to food was restricted as necessary to maintain the animal's body weight in the range of $85-90 \%$ of its free feeding weight. All procedures involving the rats were performed in compliance with institutional standards as set forth by the National Institutes of Health Guide for the Care and Use of Laboratory Animals.

\section{Presurgical training}

Before all surgical procedures, rats were trained to forage for food pellets scattered on the floor of a gray wooden cylinder $(76 \mathrm{~cm}$ in diameter; 50 $\mathrm{cm}$ high). The floor was composed of gray photographic backdrop paper that could be changed between sessions. The inside of the cylinder was featureless except for a white cue card occupying $\sim 100^{\circ}$ of arc attached to the wall, which was maintained at the same position throughout training. A black floor-to-ceiling curtain (2.5 $\mathrm{m}$ in diameter) surrounded the cylinder and four uniformly arranged lamps were located above the cylinder to provide illumination. A color video camera (model XC-711; Sony) was centered above the cylinder. Training continued until all animals spent most of their time in the cylinder foraging for food pellets (5-7 d). For both training and recording sessions described below, white noise was played from an overhead hidden speaker on the ceiling to mask auditory cues.

\section{Lesions and electrode implantation}

All animals were anesthetized with Nembutal $(40 \mathrm{mg} / \mathrm{kg}$, i.p.) and given atropine sulfate $(5 \mathrm{mg} / \mathrm{kg}$, i.p.) to prevent respiratory distress. The animals were then placed in a Kopf stereotaxic instrument (David Kopf Instruments) and an incision was made to expose the skull. Rats receiving RSP lesions $(n=15)$ had small holes drilled into their skull above the RSP at 10 sites based on coordinates provided by Paxinos and Watson (1998) and modified by previous histological results (Table 1). The RSP was electrolytically lesioned $(n=8)$ by lowering a no. 0 stainless steel insect pin that was insulated by epoxylite (except for its $1 \mathrm{~mm}$ pointed tip) into the RSP. The insect pin was allowed to sit for $1 \mathrm{~min}$ before current was passed. At each site, a $0.3 \mathrm{~mA}$ current was passed through the insect-pin electrode for $30 \mathrm{~s}$. The insect pin was then retracted and lowered into the next lesion site. Neurotoxic lesions of the RSP $(n=7)$ were produced by infusing $0.3 \mu \mathrm{l}$ of a $100 \mathrm{~mm}$ solution of NMDA (dissolved in $0.9 \%$ saline) into the RSP. The solution was infused at a rate of $0.1 \mu \mathrm{l} / \mathrm{min}$ through a 1 $\mu l$ Hamilton syringe (Hamilton Company). During infusion, the syringe was lifted $\sim 0.1 \mathrm{~mm}$ to aid diffusion. After each injection, the syringe was left in place for 3 min before being slowly removed. The needle was wiped with distilled water after each injection and the syringe was tested to ensure that it was not clogged before being lowed to the next injection site.
All animals (RSP: $n=15$; control: $n=18$ ) received implantation of recording electrodes above the $\mathrm{ADN}$ using the following coordinates: 1.9 $\mathrm{mm}$ posterior to bregma, $1.3 \mathrm{~mm}$ lateral to bregma, and $3.7 \mathrm{~mm}$ below the cortical surface (Paxinos and Watson, 1998). Electrodes were constructed and surgically placed using methods similar to those described previously (Kubie, 1984; Taube, 1995). Briefly, each electrode consisted of a bundle of $1025-\mu \mathrm{m}$-diameter nichrome wires that were insulated except at the tip. The wires were threaded through a 26 -gauge stainless steel cannula that was moveable in the dorsal/ventral direction after being fixed to the skull using dental acrylic.

\section{Cell screening procedures}

After $7 \mathrm{~d}$ of recovery from surgery, electrodes were monitored or "screened" for cellular activity while the animals foraged for food in the cylinder. To detect cell activity, electrical signals were passed through a field-effect transistor in a source-follower configuration. Signals were amplified by a factor of 10,000-50,000 (Grass Instruments), bandpass filtered ( $300-10,000 \mathrm{~Hz}, \geq 3 \mathrm{~dB}$ /octave) and sent through a dual window discriminator (BAK Electronics) for spike discrimination. The position and directional orientation of the rat was determined by an automated video tracking system (Ebtronics). This video tracking hardware provided $x$ and $y$ coordinates of red and green light-emitting diodes (LED) secured $10 \mathrm{~cm}$ apart above the head and back of the animal, respectively. The HD of the animal was determined by the relative position of the red and green LED's. Monitoring of cellular activity continued until each of the 10 implanted wires had been examined for HD cells or other cellular activity. If no HD cells were detected, the electrode was advanced 25-50 $\mu \mathrm{m}$ and the animal was returned to its home cage and monitored again either $4 \mathrm{~h}$ later or the next day. If an HD cell was identified, the cell was recorded for an 8 min session and its firing properties were evaluated. Without detaching the recording cable, the animal was then removed from the cylinder and placed in a cardboard box located outside the curtained off area and the apparatus was then prepared for three different tests.

Landmark rotation test. The experiment consisted of three separate 8 min sessions (Fig. 1A). First, a standard session (standard 1) was performed in which HD cell activity was monitored and recorded while the rat foraged for food pellets in the cylinder. This session was followed by a rotation session in which the visual landmark was rotated $90^{\circ}$ in either the clockwise (CW) or counterclockwise (CCW) direction. For two cells in the electrolytic RSP lesion group, the cue card was rotated $180^{\circ}$. The rotation of the cue always occurred while the animal was in the cardboard box (i.e., out of view of the animal). Finally, the third session consisted of returning the cue card to its original position during the first session (standard 2). Between each testing session the floor paper was replaced with clean paper to prevent the animals from using markings on the floor or wall as orientation cues. Animals were given disorientation treatments before each recording session by placing the animal in a cardboard box and rotating it slowly $(0.2-0.5 \mathrm{~Hz})$ while the experimenter simultaneously walked around the testing room twice. This disorientation treatment has been used in previous studies (Taube, 1995; Goodridge et al., 1998) and was used in this test to prevent the animal from using idiothetic cues to maintain orientation from one session to the next.

Dark test. The test consisted of recording HD cell activity with the visual landmark removed and the room lights turned off (Fig. $1 A$ ). Before the dark test, the animals were removed from the cylinder and placed in a cardboard box while the floor paper was replaced and the cue card was removed from the cylinder. To start the test, the room lights were turned off and the rat was gently placed in the cylinder and allowed to retrieve food pellets for $8 \mathrm{~min}$. Similar to previous studies (Goodridge et al., 1998; Golob and Taube, 1999), animals were not disoriented before being placed in the cylinder for dark testing. To track the HD of the rat, the red and green LEDs remained on during the dark session. Although rats cannot see well in the red color spectrum (Neitz and Jacobs, 1986), they can see under green light. Thus, it is important to demonstrate that the low level of green light present in the dark conditions was insufficient for them to use uncontrolled visual cues that may be present in the environment. To determine their ability to use a prominent visual cue in the dark in the presence of the green LED, we conducted a test on three 


\section{A Landmark Rotation and Dark test}

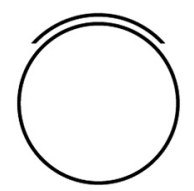

Standard 1

(8min)

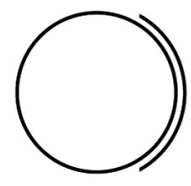

Rotation

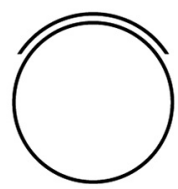

Standard 2 (8min)

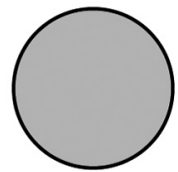

Dark test (8min)

\section{B Dual-Chamber Test}

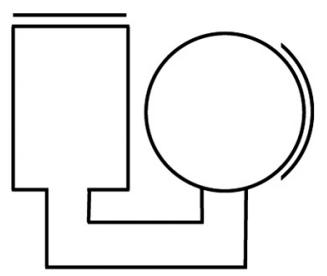

Cylinder 1 (4min)

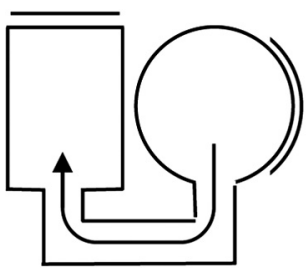

Rectangle (10min)

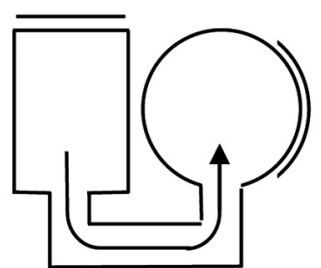

Cylinder 2 (4min)

Figure 1. A, Overhead view of the landmark rotation and dark test sessions. Each session, except the dark test, was separated by disorientation treatment. The floor paper was changed between sessions and animals. White noise was played from an overhead location. $\boldsymbol{B}, 0$ verhead view of the dual-chamber test sessions. The door to the rectangle was closed when the animal entered the rectangle. The door to the cylinder was closed during both cylinder sessions (cylinder 1 and cylinder 2).

HD cells from three intact rats where a shorter white cue card was fixed along the upper half of the recording cylinder $(36 \mathrm{~cm}$ from floor). The shortened cue card subtended the same arc along the wall as the regular cue card in the standard sessions. This cue did not exert stimulus control over the preferred direction for each cell when rotated $90^{\circ}$ in darkness (deviation from the expected shift: $-120^{\circ},-180^{\circ}$, and $-120^{\circ}$ ), even though the same cue card provided strong stimulus control in lighted conditions (deviation from the expected shift: $-24^{\circ}, 0^{\circ}$, and $-18^{\circ}$ ). Thus, in addition to the fact that there were no obvious visual cues in the environment that the animal could use for orientation, the amount of light available from the LEDs did not appear to be sufficient for HD cells to use a salient visual landmark for orientation. Thus, it is unlikely that the animals were capable of using a smaller, less prominent visual landmark in the environment for orientation.

After the $8 \mathrm{~min}$ dark test was complete, animals were removed from the cylinder and a final $8 \mathrm{~min}$ standard session (standard 3) was conducted in which the room lights were turned back on, the floor paper was replaced, and the cue card was returned to the original position. Rats were given a disorientation treatment before being placed in the cylinder for Standard 3.

Dual-chamber test. The dual-chamber apparatus involves the animal locomoting from the familiar cylinder into a novel enclosure (Taube and Burton, 1995). Figure $1 B$ illustrates an overhead view of the dualchamber apparatus which is composed of two gray colored compartments, a cylinder similar to that described above (76 cm in diameter) and a rectangle $(51 \mathrm{~cm} \times 69 \mathrm{~cm})$ interconnected by a narrow U-shaped passageway $(41 \mathrm{~cm} \times 15 \mathrm{~cm})$. The walls along one side of the alleyway were slanted by $\sim 15^{\circ}$ in order for the overhead video camera to view all areas of the passageway. A section of wall in each enclosure could be removed to control access between the two sections and the passageway. The walls of the rectangle were featureless except for a white cue card positioned along the wall such that it was rotated $90^{\circ} \mathrm{CCW}$ with respect to the cue card in the cylindrical compartment. The floors of the cylinder and rectangle were composed of gray photographic backdrop paper. The passageway contained a gray painted wooden floor. Because the dualchamber's cylinder was similar to the cylinder the rats had been trained and screened in for several weeks, the cylinder was considered a familiar environment to the animals. The passageway and the rectangle repre-

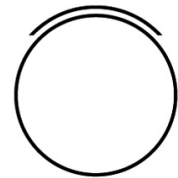

Standard 3 (8min) sented a novel environment because the animals had no previous exposure to them.

The procedure for the dual-chamber apparatus experiment consisted of three phases. First, the animal was placed in the cylindrical compartment with the door to the passageway closed (cylinder 1 session). After allowing the animal to forage for scattered food pellets for $4 \mathrm{~min}$, the cylinder compartment door was opened and the animal was free to walk into the passageway and enter the rectangle. Upon entering the rectangle, the hidden door was closed, trapping the animal inside the rectangle chamber while activity of the HD cell was monitored for 10 min (rectangle session). After completion of the rectangle session, the door to the rectangular compartment was opened and the rats were allowed to locomote back through the passageway to the cylinder, in which they were again trapped inside while HD cell activity was monitored for another $4 \mathrm{~min}$ (cylinder 2). The dual-chamber apparatus experiment was conducted only once per animal since the task requires the rectangular compartment to be novel. Thus, only one $\mathrm{HD}$ cell recording session was collected per animal in this task.

\section{Data analysis}

The automated video-computer tracking system, sampling at $60 \mathrm{~Hz}$, recorded the number of spikes occurring during each sample period while simultaneously recording the $x, y$ positions of each LED. Data analysis was accomplished off-line using custom software (LabView, National Instruments). The animal's HD was sorted into $606^{\circ}$ bins. Basic directional characteristics of the recorded cells were determined by examining cellular activity during the standard 1 cylinder session. Cells from lesioned and control animals were compared on measures of peak firing rate, background firing rate, directional firing range directional information content, and anticipatory time interval (ATI) (Taube et al., 1990a). The preferred direction was defined as the directional bin with the highest firing rate. The peak firing rate was defined as the firing rate in the bin corresponding to the cell's preferred direction. The directional firing range was defined as the width at the base of a triangle fit to a firing rate versus HD plot. The background firing rate was the average firing rate of all bins $18^{\circ}$ outside the cell's directional firing range. Directional information content is a measure of how many bits of head direction information is conveyed by each spike (Skaggs et al., 1993) and was calculated by the following formula: Directional Information Content $=\Sigma p_{i}\left(\lambda_{i} / \lambda\right) \log _{2}\left(\lambda_{i} / \lambda\right)$, where $p_{i}$ is the probability that the head pointed in the $i$ th directional bin, $\lambda_{i}$ is the mean firing rate for bin $i$, and $\lambda$ is the mean firing rate across all directional bins.

The ATI is a measure of the amount of time that cell firing best predicts where the animal will be pointing its head in the future. We compared the ATI of cells from control and RSP lesioned animals during the standard 1 session using the methods of Blair and Sharp (1995). Firing rate versus HD plots tuning functions were first constructed for CW and CCW directions. From these two functions, we then determined the difference between their preferred firing directions (i.e., separation angle). The spike record was then shifted forwards and backwards in time in steps of $16.67 \mathrm{~ms}$ (the maximum temporal resolution of the recording hardware) and the separation angle between the CW and CCW functions for head movements $\geq 90^{\circ}$ s was computed for each shift. The spike series was shifted incrementally \pm 6 times $( \pm 100 \mathrm{~ms}$ ) relative to the HD series, providing 13 values of CW-CCW separation angles. A scattergram was then constructed from the $13 \mathrm{CW}-\mathrm{CCW}$ separation angles and their corresponding time shift. The $x$-intercept of the best-fit line of this plot is referred to as the ATI and is equivalent to the amount of time that the spike series has to be shifted to achieve overlapping CW and CCW functions. 
Circular statistics (Batschelet, 1981) were used to determine the stability of the directional signal between the landmark rotation sessions, dark testing sessions, and the three dual-chamber sessions. Angular shift scores across testing sessions were calculated using a cross-correlation method (Taube and Burton, 1995). This approach involves shifting the firing rate versus HD function of the first session in $6^{\circ}$ increments while correlating this shifted function with the nonshifted function from the other session. The amount of shift required to produce the maximal Pearson $r$ correlation between the two sessions is defined as the angular shift score between the sessions. These values were then subjected to Rayleigh tests (Batschelet, 1981) to determine whether the scores were clustered randomly or whether the preferred directions tended to shift in the same direction and amount. The Rayleigh test computes a mean vector length $(r)$ for the distribution of angular shift values. This $r$ value, which ranges between 0 and 1, represents the variability in the shift angles for the group, with values of 1.0 indicating an absence of variability. ANOVAs, planned contrasts, and $t$ tests were used for group comparisons of the absolute angular shift scores produced during the different test sessions. For ANOVAs, violations of homogeneity of variance were corrected using Welsh's $F$ test (Tabachnick and Fidell, 2007).

\section{Histological analysis}

At the completion of the experiment, animals were deeply anesthetized with sodium pentobarbital and a small anodal current $(20 \mu \mathrm{A}, 10 \mathrm{~s})$ was passed through one to four wires to conduct a Prussian blue reaction. The rats were then perfused intracardially with saline followed by a $10 \%$ formalin solution. Each brain was removed from the skull and was postfixed in a $10 \%$ formalin solution containing $2 \%$ potassium ferrocyanide for at least $24 \mathrm{~h}$. The brains were then cryoprotected in a $20 \%$ sucrose solution for $24 \mathrm{~h}$, and were then frozen and cut coronally at $30 \mu \mathrm{m}$ sections with a cryostat. Every section was taken through the ADN and every third section was taken through the RSP. Sections were mounted on glass microscope slides, stained with thionin, and examined under light microscopy to determine the location of recording sites and evaluate the lesions. To quantify the extent of electrolytic and neurotoxic damage to the RSP, digital images were captured at 10 rostral-caudal levels $(2.12,2.8,3.6,4.3,5.2,5.8,6.72,7.3,8$, and $8.8 \mathrm{~mm}$ posterior to bregma) provided by Paxinos and Watson (1998). The area of undamaged tissue in the RSP was calculated at each rostral-caudal level using ImageJ software (http://rsb.info.nih.gov/ij/index.html). Tissue was considered undamaged if it contained healthy neurons and few glial cells. Once the area of undamaged tissue was calculated, the area of spared tissue was summed across the three sections and compared with an average area measured in the control rats. The total amount of damage was calculated using the following formula: Tissue damaged $=$ [average area of RSP in control rats (pixels ${ }^{2}$ ) - total area of spared RSP tissue in lesioned rats $\left(\right.$ pixels $^{2}$ )/average area of RSP in control rats $\left(\right.$ pixels $\left.\left.^{2}\right)\right] \times 100 \%$.

\section{Results}

\section{Lesions of the retrosplenial cortex}

Based on cytoarchitectural differences, the RSP can be divided into two parts, the granular and dysgranular cortices (van Groen and Wyss, 1990, 1992, 2003; Wyss and Van Groen, 1992). The granular RSP can be further subdivided into granular-a and granular-b RSP regions based on the work of Wyss and Sripanidkulchai (1984). HD cells have been identified within the granular and dysgranular RSP (Chen et al., 1994; Cho and Sharp, 2001). Furthermore, each RSP subdivision has extensive connections with areas of the limbic system that contain HD cells. For example, the PoS has strong reciprocal connections with all subdivisions of the RSP (Wyss and Van Groen, 1992). In contrast, the $\mathrm{ADN}$ has a stronger reciprocal relationship with the granular portions of RSP, especially the granular-b portions (van Groen and Wyss, 1990, 1992, 2003). Although these differences in connectivity suggest that each RSP subdivision may influence
HD cell activity independently, recent work has shown that the RSP subdivisions are heavily interconnected (Shibata et al., 2009) and that the caudal regions of the retrosplenial cortex may be particularly important for processing spatial information (defined by Vann et al., 2003, as the portion of the RSP extending from $-4.8 \mathrm{~mm}$ to $-9.3 \mathrm{~mm}$ posterior to bregma). Thus, to determine whether the RSP is involved in processing the HD cell signal, we designed our experiment to lesion as much of the RSP as possible, and paid particular attention to whether we lesioned the caudal portions. Fifteen rats received either electrolytic $(n=$ 8 ) or neurotoxic NMDA $(n=7)$ lesions of the RSP.

Figure 2 shows plates from Paxinos and Watson (1998) of coronal sections through the RSP at 10 rostral-caudal levels. Figure 2, $A$ and $B$, displays the extent of the largest (gray) and smallest (black) lesion for electrolytic and neurotoxic lesioned rats, respectively. Overall, RSP lesions were large, with electrolytic lesion size estimates ranging from 72 to $96 \%$ (mean \pm SEM: $87.3 \pm$ $3.03 \%$ ), and neurotoxic lesions covering from 73 to $87 \%$ (mean \pm SEM: $80.6 \pm 1.97 \%$ ) of the total RSP. Although the extent of neurotoxic lesions was slightly smaller than electrolytic lesions, the difference did not reach statistical significance $\left(t_{(13)}=\right.$ $-1.78, p=0.10)$. Importantly, the range of estimated neurotoxic RSP damage is comparable to previous reports demonstrating impairments in spatial tasks after neurotoxic lesions (Vann and Aggleton, 2002, 2004; Harker and Whishaw, 2004; Lukoyanov et al., 2005; Pothuizen et al., 2008; Wesierska et al., 2009). For both lesion groups, healthy tissue was mostly confined to the extreme caudal portions of the RSP, generally past $-8.0 \mathrm{~mm}$ from bregma. Three rats from the electrolytic lesion group and 1 rat from the neurotoxic lesion group showed sparing in rostral portions of the RSP. Spared tissue in these animals was generally confined to granular subdivisions.

Figure 3, $A, B$, and $C$, displays representative coronal sections through the RSP from a control, electrolytic lesion, and neurotoxic lesion rat, respectively. Electrolytic lesions frequently extended into the adjacent motor and parietal cortices, and in all cases included portions of the cingulum bundle, which is known to carry axons between the anterior thalamus, hippocampus, and parahippocampal regions (Domesick, 1970). Lesions approached the adjacent PoS in only 5 cases ( 3 electrolytic and 2 neurotoxic); however, this additional damage was never $>5 \%$ of the total volume of the PoS. Because previous studies have shown that PoS lesions disrupt landmark control over HD cell orientation (Goodridge and Taube, 1997; Yoder and Taube, 2008), we consider the influence of this subgroup on the results in the landmark rotation test discussed below. For neurotoxic lesions, damage in most cases included the adjacent motor and parietal cortices (similar to the electrolytic lesions), and in three animals, a small unilateral portion of the CA1 hippocampal subregion. Unintentional damage to the parietal cortex was minimal (on average $<10 \%$ ) and was not of major concern because a previous study showed that the $\mathrm{HD}$ signal in the $\mathrm{ADN}$ is processed independently of the parietal cortex (Calton et al., 2008). However, unintentional damage of the cingulum bundle may have contributed to the results presented below because it is well known that selective damage of this fiber pathway can disrupt accurate performance in spatial tasks (Aggleton et al., 1995; Neave et al., 1996; Warburton et al., 1998). Because neurotoxic lesions are known to spare fibers of passage (Jarrard, 1989), it was unlikely that NMDA injections damaged the cingulum bundle or other fibers within the RSP of the neurotoxic lesion group. Thus, differences between the two lesion types were addressed by comparing cell activity between each lesion and control groups. 
A
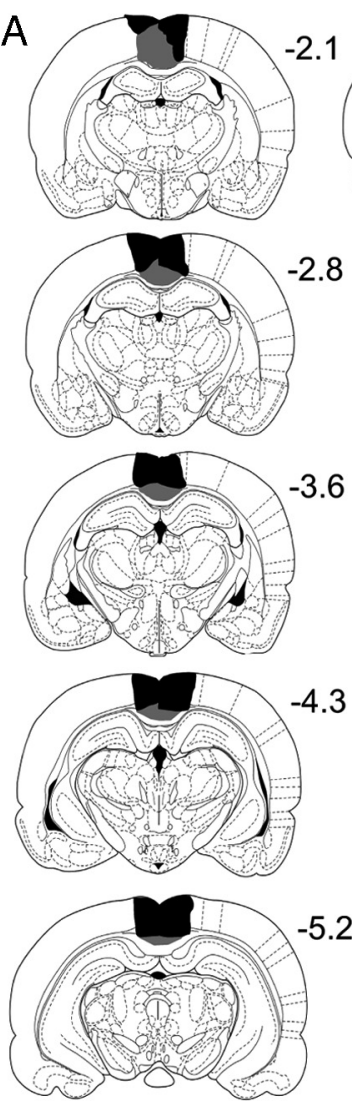

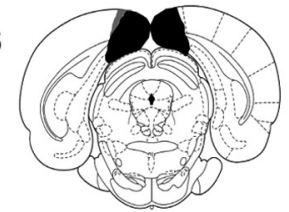

$-2.1$

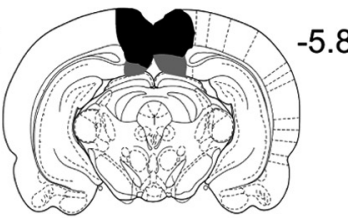

$-2.8$

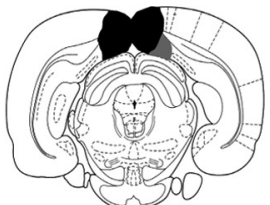

$-4.3$

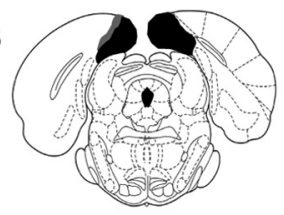

$-5.2$

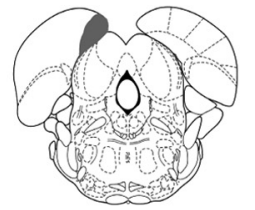

$\mathrm{B}$

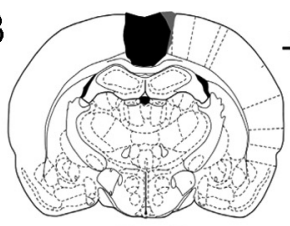

$-6.7$
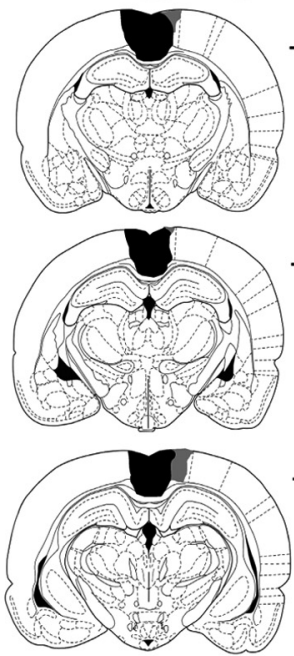

$-8.8$

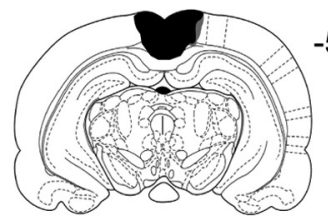

$-2.1$

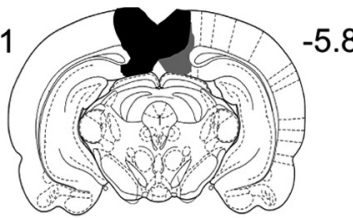

$-2.8$

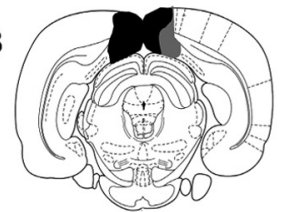

$-3.6$

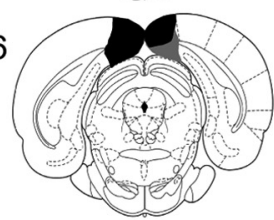

$-4.3$

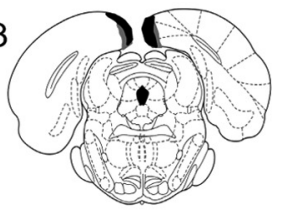

$-5.2$

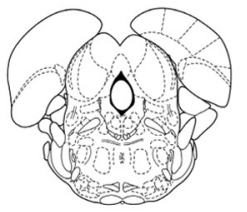

$-7.3$

$-8.8$

Figure 2. Selected plates from Paxinos and Watson (1998) showing the rostral-caudal extent of the RSP at relative coordinates from bregma. $\boldsymbol{A}, \boldsymbol{B}$, The extent of the largest (gray) and smallest (black) RSP lesions are shown for electrolytic $(\boldsymbol{A})$ and neurotoxic lesion $(\boldsymbol{B})$ groups.

\section{Head direction cells in the anterodorsal thalamus}

Electrode arrays were placed in the ADN of each animal from RSP lesion $(n=15)$ and control groups $(n=18)$, and histological analyses verified the electrodes to have advanced completely through the ADN of each animal. For each group the number of cells with HD and nondirectional correlates was counted within the dorsal-ventral range of the ADN. Cells were classified as HD cells if they fired maximally when the animal was pointing its head in a specific direction (the preferred firing direction) independent of its location and behavior, such as grooming or eating. For 16 control rats (two were removed from this analysis because of poor histology), 133 cells were recorded from the ADN with 63 of these cells classified as HD cells $(47.4 \%)$. For neurotoxic lesioned rats, 27 of 61 cells $(44.3 \%)$ were classified as HD cells, and in the electrolytic group, 19 of 46 cells $(41.3 \%)$ were classified as HD cells. A one-way ANOVA conducted on the incidence rate of HD cells per animal did not indicate a significant difference between electrolytic (41.5 $\pm 5.29 \%)$, neurotoxic (50.5 $\pm 10.9 \%)$, and control groups $\left(50.7 \pm 4.91 \% ; F_{(2,30)}=0.556, p=0.58\right)$. Only cells considered to be well isolated from background noise were considered for subsequent analysis (control, $n=45$; electrolytic, $n=14$; neurotoxic, $n=18$ ).

Although control, electrolytic lesion, and neurotoxic lesion groups had comparable numbers of HD cells within their ADN, the cells in RSP lesioned animals displayed less direction-specific activity than those recorded in control rats. The left side of Figure 4 shows firing rate versus HD plots for representative HD cells recorded from control $(A)$, electrolytic lesion $(B)$, and neurotoxic lesion $(C)$ rats. As is clearly illustrated by the plots, HD cells from lesioned rats had significantly wider tuning curves. This observation was confirmed by a significant one-way ANOVA conducted on the directional firing range of HD cells from RSP lesion (electrolytic, $131.0 \pm 6.73^{\circ}$; neurotoxic, $139.9 \pm 7.79^{\circ}$ ) and control animals $\left(98.8 \pm 3.76^{\circ} ; F_{(2,76)}=17.8, p<0.001\right.$; electrolytic vs neurotoxic, $t_{(74)}=-0.916, p=0.36$; electrolytic vs control, $t_{(74)}=3.86, p<0.001$; neurotoxic vs control, $t_{(74)}=5.41$, $p<0.001)$. RSP lesions also significantly reduced the directional information content of HD cells $\left(F_{(2,76)}=3.89, p=0.03\right.$; electrolytic vs neurotoxic, $t_{(74)}=0.176, p=0.86$; electrolytic vs control, $t_{(74)}=-1.99, p=0.05$; neurotoxic vs control, $t_{(74)}=2.41, p=$ 0.02 ), which measures the amount of information (in bits) that a spike conveys, or how well the occurrence of a HD cell spike predicts an animal's HD (electrolytic, $0.99 \pm 0.11$ bits; neurotoxic, $0.95 \pm 0.10$ bits; control, $1.30 \pm 0.09$ bits). The lesions did not, however, cause a significant change in the peak firing rate (electrolytic, $56.0 \pm 9.91 \mathrm{spikes} / \mathrm{s}$; neurotoxic, $42.3 \pm 4.65$ spikes/s; control, $44.0 \pm 3.05$ spikes/s; $F_{(2,26.5)}=0.772, p=$ 0.472 ), or background firing rate of HD cells (electrolytic, $1.74 \pm 0.36$ spikes/s; neurotoxic, $2.12 \pm 0.33$ spikes/s; control, $1.64 \pm 0.21$ spikes $\left./ s ; F_{(2,76)}=0.766, p=0.47\right)$. Figure $5, A$ and $B$, plots the distributions of directional firing range and directional information content values for each cell in each group, respectively.

The larger firing range of HD cells recorded in RSP lesioned rats could arise from instability of the preferred firing direction rather than an actual change in the directional firing range. To evaluate this possibility, we constructed plots showing each cell's preferred firing direction as a function of time. Figure 4, right, shows the corresponding HD versus time plots for control and lesion animals. Each circle represents the animal's HD and time 

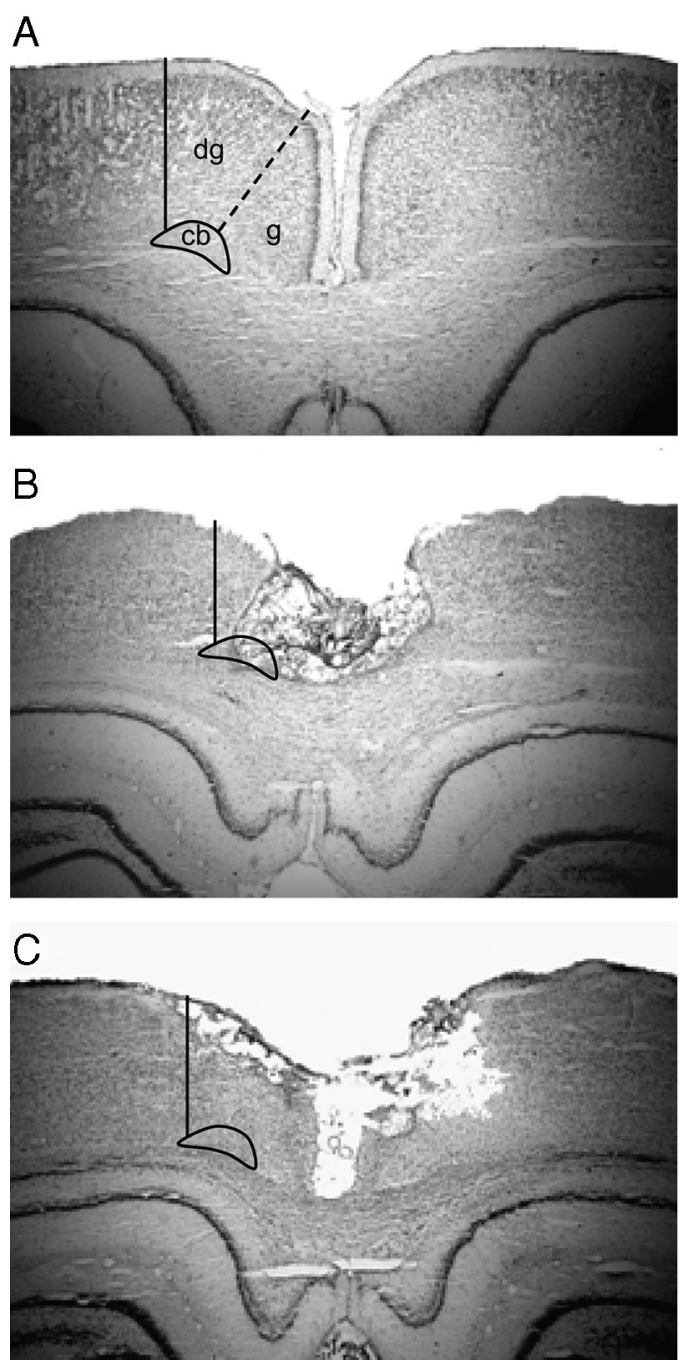

Figure 3. A, Representative section at $-4 \mathrm{~mm}$ relative to bregma from a control rat. The solid line shows the lateral border of the RSP and the broken line indicates the border between the granular $(\mathrm{g})$ and dysgranular (dg) subdivisions of the RSP. Notice the location of the cingulum bundle (cb) outlined with a solid line. $\boldsymbol{B}$, Representative section at $-4 \mathrm{~mm}$ relative to bregma from an electrolytic lesioned rat. Note that the lesion includes portions of the cingulum bundle. $C$, Representative section at $-4 \mathrm{~mm}$ relative to bregma from a neurotoxic lesioned rat. Note that the cingulum bundle is intact.

(resolution $=1 / 6$ of a second) in which the cell fired at a rate $\geq 50 \%$ of its peak firing rate (obtained from the overall firing rate vs HD plot). Thus, the stability of the preferred firing direction can be monitored across the session. The plots clearly illustrate that control animals displayed stable peak firing rates clustered within a narrow range of directions throughout the 8 min recording session. In contrast, the preferred firing directions of HD cells recorded in RSP lesioned animals frequently drifted during the session. In some cases, the drift was steady across time (Fig. $4 B$ ), but in other cases, the drift frequently changed directions during the session (e.g., Fig. $4 C$ shows that the cell's preferred direction initially drifted $\mathrm{CW}$ for the first 2-3 min and then drifted CCW the last $2 \mathrm{~min}$ ). To provide an estimate in the amount of drift, we calculated the mean absolute shift in the preferred direction between sequential $1 \mathrm{~min}$ epochs (i.e., the mean change in preferred direction between $0-1$ min and 1-2 min, between 1-2 min and 2-3 min, etc.). This analysis indicated that the drift was relatively slow over the $8 \mathrm{~min}$ period and ranged from 6 to $48.9^{\circ} / \mathrm{min}$ for the lesion group. A similar range of drift
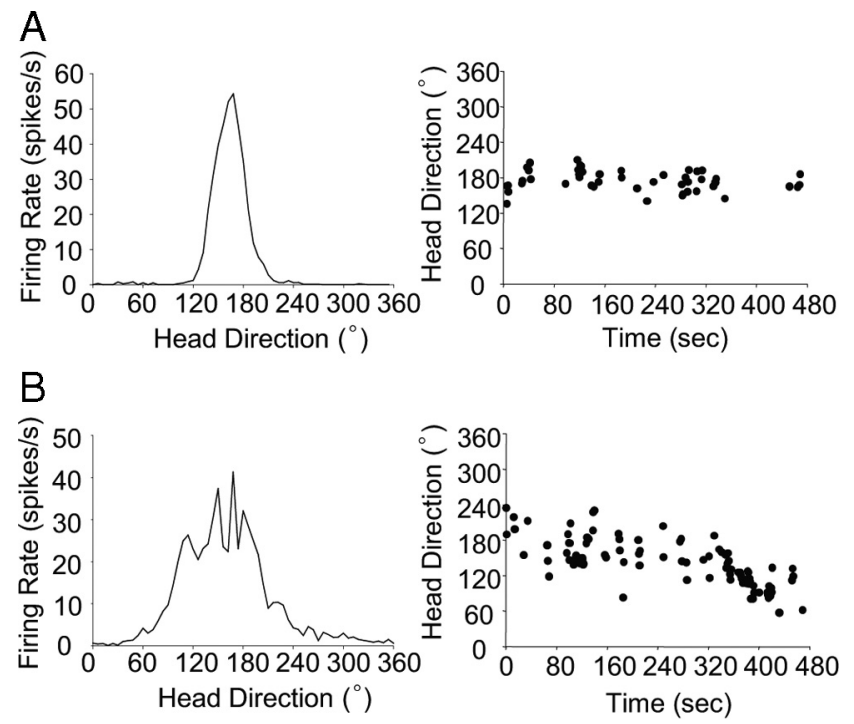

C
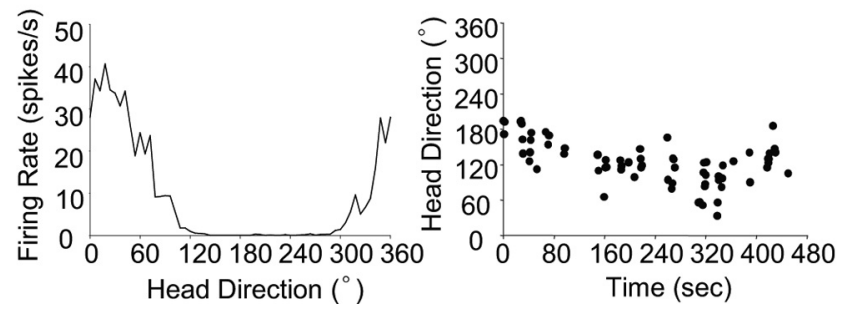

Figure 4. $\boldsymbol{A}-\boldsymbol{C}$, Left, Representative HD cells from a control $(\boldsymbol{A})$, electrolytic RSP lesion $(\boldsymbol{B})$, and neurotoxic RSP lesion $(\boldsymbol{C})$ animals. Right, Corresponding HD versus time plot for cells when they fired $\geq 50 \%$ of their maximum firing rate (as measured from the entire 8 min session). Notice that the preferred direction of the HD cell from the control animal showed little fluctuation throughout the standard 1 session. In contrast, the preferred directions of HD cells in the RSP animals displayed significant drift during the standard 1 session.

rates was observed in control animals ( 4.28 to $49.7^{\circ} / \mathrm{min}$ ). Importantly, however, 15 of 32 cells drifted $>18^{\circ} / \mathrm{min}$ in the lesion group compared with only 5 of 45 cells from the control group. This difference reached statistical significance $\left(\chi^{2}(1)=12.4, p<\right.$ $0.001)$. It is noteworthy, however, that the rate of drift in RSP lesioned rats is considerably slower compared with drift rates observed in burst cells in animals with lesions of the vestibular system (Muir et al., 2009; Yoder and Taube, 2009).

We also estimated the magnitude of preferred direction drift by calculating the angular deviation for the points in each HD versus time plot (Batschelet, 1981). It was reasoned that the drifting nature of HD cells in the lesioned group should result in greater angular deviation values compared with cells in the control group. Consistent with this hypothesis, the average angular deviation in peak firing rate points was greater for cells in the lesioned groups (electrolytic, $31.1 \pm 3.78^{\circ}$; neurotoxic, $31.6 \pm$ $1.92^{\circ}$; control, $\left.24.1 \pm 1.31^{\circ}\right)$. This difference was confirmed by a significant ANOVA and group comparisons $\left(F_{(2,76)}=5.219 ; p=\right.$ 0.008 ; electrolytic vs neurotoxic, $t_{(74)}=-0.132, p=0.895$; electrolytic vs control, $t_{(74)}=2.35, p=0.02$; neurotoxic vs control, $\left.t_{(74)}=2.75, p=0.007\right)$. With respect to lesion size, the rat that demonstrated the greatest intrasession drift had a relatively large lesion (95\%). In contrast, another rat that had a large number of drifting cells in the standard sessions had an RSP lesion that was comparable in size to the group average (81\%). Thus, there were no noticeable differences between animals with different lesion types or sizes. Moreover, the rats that displayed the largest intra- 
A

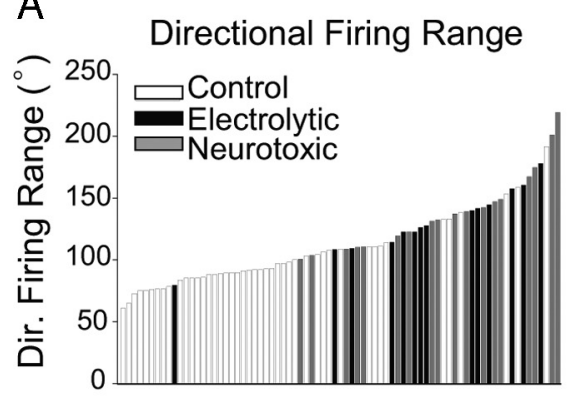

C

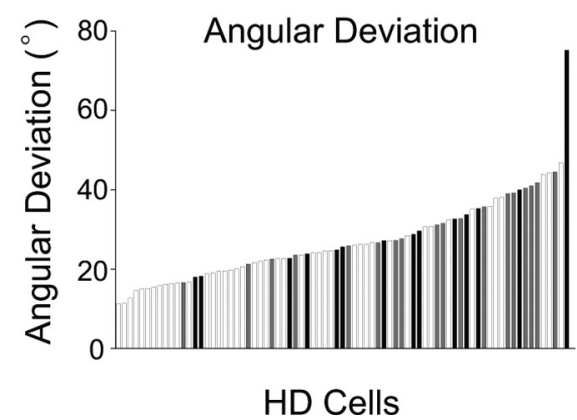

B

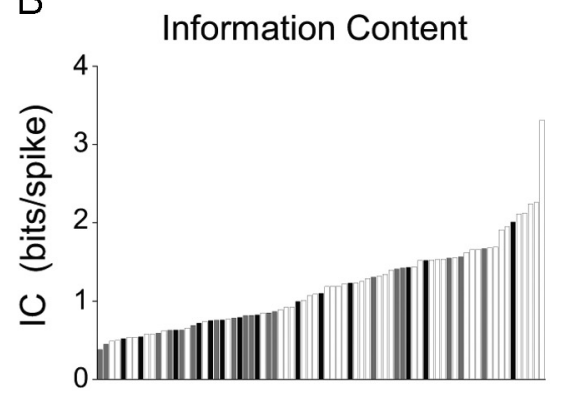

D

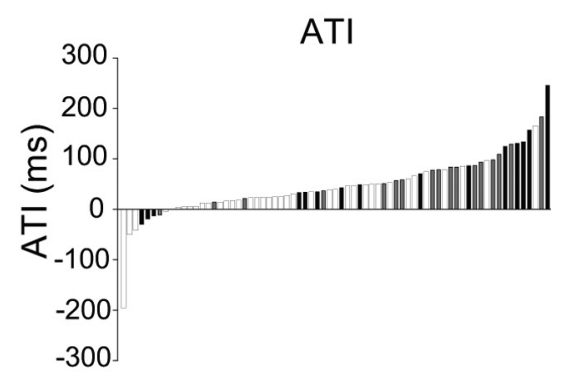

\section{HD Cells}

Figure 5. $\boldsymbol{A}-\boldsymbol{D}$, Plots showing the directional firing range $(\boldsymbol{A})$, information content $(\boldsymbol{B})$, angular deviation (C), and ATI values (D) for HD cells recorded in control (white bars), electrolytic RSP lesion (black bars), and neurotoxic RSP lesion (gray bars) groups. In general, HD cells from RSP lesioned animals had higher directional firing ranges, lower information content values, higher angular deviation values, and higher ATI values than controls.

session drift had similar impairments as other animals in the other experiments (i.e., landmark rotation, dark, and dualchamber task).

The results above reinforce the possibility that intrasession drift contributes to the wider tuning curves observed in RSP lesioned rats. If this possibility is true, then at short time intervals, in which the drift in the preferred direction is small, the tuning width of cells in lesioned animals should approximate the width of control cells. To address this prediction, we constructed firing rate versus $\mathrm{HD}$ plots for each minute of a recording session and then aligned the tuning curve to a particular HD. We then generated a plot that averaged the tuning curves across the $1 \mathrm{~min}$ time periods. From the averaged plots we obtained the directional firing range for each of the cells. Despite these short time intervals, however, RSP lesioned rats continued to display significantly broader HD cell tuning curves (electrolytic, $132.5 \pm 6.71^{\circ}$; neurotoxic, $\left.144.1 \pm 10.45^{\circ}\right)$ compared with those recorded in control rats (control, $105.7 \pm 5.06^{\circ} ; F_{(2,74)}=8.76 ; p<0.001$; electrolytic vs neurotoxic, $t_{(74)}=-0.918, p=0.361$; electrolytic vs control, $t_{(74)}=2.49, p=0.02$; neurotoxic vs control, $t_{(74)}=$ $3.90, p<0.001)$. Moreover, the tuning width of HD cells in the lesioned groups did not differ from the width values calculated using the traditional method (electrolytic, $t_{(26)}=-1.64, p=$ 0.871 ; neurotoxic, $\left.t_{(34)}=-0.324, p=0.748\right)$. Together, the results indicate that the wider HD cell tuning curves observed in lesioned rats are not solely due to the result of intrasession drift, but rather is also a fundamental property of the cells.

The broad directional tuning of HD cells may additionally be influenced by the time interval by which each individual cell anticipates the animal's future HD, also known as the cell's ATI (Blair and Sharp, 1995; Taube and Muller, 1998). Prior work has shown that the discharge of ADN HD cells consistently anticipate the animal's future HD by $\sim 25 \mathrm{~ms}$, and the length of the ATI is strongly correlated with the width of a cell's directional tuning function, such that cells with longer ATI values have broader directional firing ranges (Blair et al., 1997; Taube and Muller, 1998). Thus, given the significantly greater directional firing ranges of HD cells in RSP lesioned animals, we hypothesized that the ATIs of cells in the lesioned groups should be larger compared with control animals. To test this prediction, we computed the ATI for each cell using the methods of Blair and Sharp (1995). Because of poor sampling for clockwise or counterclockwise movements, six cells from the control group were excluded from this analysis. A one-way ANOVA revealed that neurotoxic RSP lesions significantly increased the time by which HD cells anticipated future heading (Fig. $5 D)\left(F_{(2,28.5)}=6.55\right.$, $p=0.005$; neurotoxic vs control, $t_{(38.5)}=$ 3.45, $p=0.001)$. Electrolytic lesions did not significantly increase anticipation relative to control animals, although the difference did approach significance $\left(t_{(17.4)}\right.$ $=2.00, p=0.062$ ). Interestingly, HD cells in RSP lesioned rats anticipated future heading twice as much as control animals (electrolytic, $72.1 \pm 20.8 \mathrm{~ms}$; neurotoxic, $73.4 \pm 10.5 \mathrm{~ms}$; control, $27.2 \pm 8.34 \mathrm{~ms}$ ), a result that is similar to two studies in which ADN HD cells were recorded in PoS or interpeduncular nucleus lesioned rats (Goodridge et al., 1998; Clark et al., 2009). Finally, a correlation conducted between the absolute ATI and the magnitude of intrasession drift failed to indicate a significant relationship between these measures (angular deviation and ATI: $r=0.197, p=0.099$; $\%$ min and ATI: $r=0.188, p=0.116$ ).

It is unclear why RSP lesions would increase anticipation, but the finding presented below that RSP plays a role in processing landmark information may explain the observation of greater ATI. For instance, it is possible that the RSP reduces the anticipation of ADN HD cells by providing information about current HD in relation to environmental cues. Thus, in the absence of an intact RSP, HD cells in the ADN may become more dependent on signals conveyed by afferent inputs such as the lateral mammillary nuclei, which anticipate future heading to a larger degree than ADN HD cells (between 40 and 75 ms) (Blair and Sharp, 1998; Stackman and Taube, 1998).

To summarize, the results above indicate that lesions of the RSP increase the directional firing range, reduce the information content and stability of the preferred firing direction, and increase the time by which HD cells anticipate future heading directions. In sum, these findings indicate that RSP lesions significantly alter the directional specificity and stability of the HD cell signal. Whether these altered properties are due to poor landmark control or impaired spatial updating mechanisms when processing idiothetic cues is investigated further below.

\section{Landmark rotation test}

The observation that RSP lesions reduce the stability of their preferred firing directions is surprising given the presence of a salient visual landmark, which could be used to maintain directional orientation. Nonetheless, this result is consistent with neu- 
ropsychological and animal lesion studies showing that the RSP is required for the use of visual landmarks for accurate spatial behavior (Sutherland et al., 1988; Harker and Whishaw, 2002, 2004; Vann and Aggleton, 2004; Cain et al., 2006; Epstein, 2008). To further evaluate whether HD cells could accurately orient in relation to visual landmarks, we conducted a landmark rotation test, which involves rotating the white cue card to a new angular position within the recording cylinder (Fig. $1 \mathrm{~A}$ ). In intact animals, the preferred firing directions of $\mathrm{HD}$ cells generally shift in the corresponding direction and same angular distance as the cue card (Taube, 1995). However, we predicted that if the RSP is involved in processing visual landmark information, then the preferred firing directions of cells in RSP lesioned animals should display inaccurate shifts in response to cue card rotations.

A total of 19 HD cells from control animals, 11 from electrolytic lesion animals, and 15 from neurotoxic lesion rats were recorded in the landmark rotation series. Figure $6 A$ shows representative firing rate versus HD plots for HD cells from control and RSP lesioned animals recorded during the tests, and Figure $6 B$ shows polar plots of the amount of angular shift in the preferred firing direction between the standard 1 and rotation sessions. The plot in Figure $6 B$, left, shows that HD cells from control animals demonstrated reliable shifts of their preferred direction in the expected direction and amount as the cue card. In contrast, HD cells recorded from electrolytic and neurotoxic RSP lesion animals failed to show similar reliable shifts in their preferred directions (Fig. 6B, right). A one-way ANOVA indicated that HD cells from RSP lesion groups had greater absolute angular deviations from the expected shift (electrolytic, $40.5 \pm 11.0^{\circ}$; neurotoxic, $59.2 \pm 12.2^{\circ}$ ) compared with HD cells recorded in control rats $\left(15.2 \pm 2.73^{\circ} ; F_{(2,17.2)}=7.99 ; p=0.004\right.$; electrolytic vs neurotoxic, $t_{(23.9)}=-1.13, p=0.268$; electrolytic vs control, $t_{(11.2)}=2.24, p=0.05$; neurotoxic vs control, $t_{(15.4)}=3.51, p=$ 0.003 ). Moreover, Rayleigh tests (Fig. $6 B$ ) indicated that angular shift scores were distributed randomly for both lesion groups (electrolytic, $r=0.453$; $p=0.096$; neurotoxic, $r=0.477$; $p=$ 0.29 ), suggesting that when the cue card was rotated, HD cells shifted to random directions. It is important to note, however, that a large number of cells in the lesion groups shifted in the correct direction with the cue card (19 of 26) indicating that the landmark exerted some control over the preferred directions of HD cells in lesioned animals. This finding is especially apparent in Figure $6 B$, in which a number of angular shift values fall just short of the expected $90^{\circ}$ rotation. This observation suggests that many cells rotated in the correct direction, but not the full angular distance predicted by cue card rotation. As a final note, we found no evidence that the additional damage to the $\operatorname{PoS}(<5 \%)$ observed in five animals contributed to the present results. This session.
B
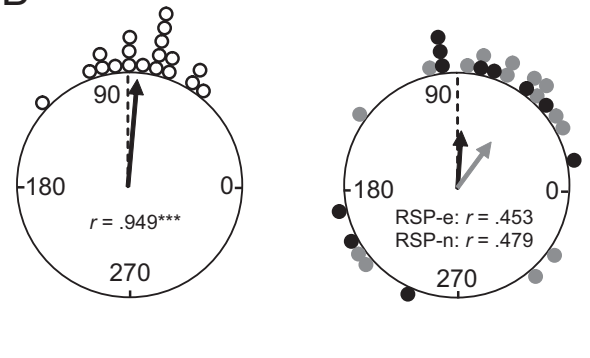

C
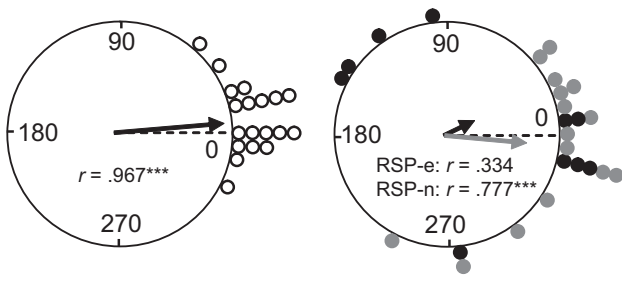

Figure 6. $\quad \boldsymbol{A}$, Responses of HD cells from representative control (top) and RSP lesioned (bottom) rats during the landmark direction of the cell from the control animal shifted in the correct direction and amount. In contrast, the preferred firing direction the magnitude of the shift in the preferred firing direction for one HD cell. For the RSP lesion group, the black circles represent the he expected vector if the shift values are perfectly predicted by the cue card rotation. Note that the mean vector lengths are considerably smaller for both lesion groups in the rotation session and for the electrolytic lesion group in the second standard

observation was confirmed by a nonsignificant comparison of angular shift values between this subgroup and the remaining RSP lesioned animals $\left(t_{(24)}=0.265, p=0.793\right)$. Moreover, there was no evidence of a significant relationship between the size of the RSP lesion and the inaccuracy of angular shifts $(r=0.132, p=$ $0.520)$.

Landmark control was further evaluated when the cue card was returned to its original position in the cylinder during the standard 2 session. In general, the preferred directions of HD cells in control animals shifted in the correct direction and angular distance as the cue card. However, some cells recorded in RSP lesioned rats failed to accurately return to their original orientation (Fig. 6A). To evaluate this response, we computed the angular shift in HD cell preferred directions between standard 1 and standard 2 sessions. Figure $6 \mathrm{C}$ displays polar plots of angular shift scores from cells recorded in control and RSP lesion groups. On average, cells recorded in RSP lesioned rats had greater absolute angular deviations from the expected return shift (electrolytic, $63.0 \pm 18.6^{\circ}$; neurotoxic, $29.6 \pm 8.24^{\circ}$ ) compared with control animals $\left(11.7 \pm 2.57^{\circ}\right)$. A significant one-way ANOVA confirmed this difference $\left(F_{(2,15.9)}=5.42 ; p=0.016\right.$; electrolytic vs neurotoxic, $t_{(12.6)}=1.64, p=0.13$; electrolytic vs control, $t_{(9.35)}=2.73, p=$ 0.023 ; neurotoxic vs control, $\left.t_{(16.7)}=2.07, p=0.054\right)$. Rayleigh 
tests indicated that angular shift values for the electrolytic group were distributed randomly ( $r=0.334 ; p=0.323)$, but nonrandomly for the neurotoxic lesion group $(r=0.777$; $p<0.001)$. Indeed, examination of the polar plot reveals that many of the cells recorded in the neurotoxic RSP lesion group shifted close to their original angular orientation, forming a cluster of angular shift values of $\sim 0^{\circ}$. This pattern of results suggests that other sources of visual information provided some compensation for the loss of RSP after neurotoxic lesions, but not after electrolytic lesions, perhaps because neurotoxic lesions spared cingulum bundle fibers and electrolytic lesions frequently damaged them. Cingulum bundle fibers include fibers from the dorsal hippocampal commissure (Swanson, 1992) that convey projections from the PoS to the ADN. Thus, because lesions of the PoS are known to disrupt cue control in ADN HD cells (Goodridge and Taube, 1997) and in lateral mammillary nuclei HD cells which project to the ADN (Yoder and Taube, 2008), it is likely that PoS fibers were transected in the electrolytic lesion group.

\section{Dark test}

Previous work has shown that in the absence of visual information (i.e., in darkness), HD cells can generally maintain their preferred firing direction (Goodridge et al., 1998; Golob and Taube, 1999; Calton et al., 2008), suggesting that the HD cell system can use nonvisual sources of information such as idiothetic or olfactory cues to maintain a stable orientation. The processing of idiothetic information for directional stability, or angular path integration, is of particular interest because evidence from animal lesion studies suggests that the RSP is required for navigation based on path integration (Cooper and Mizumori, 1999; Cooper et al., 2001; Whishaw et al., 2001). Furthermore, we described earlier that the preferred directions of HD cells in RSP lesioned rats displayed intrasession drift during standard sessions. This drift may have been due to poor spatial updating of idiothetic cues as the rat locomoted around the apparatus. To determine whether the RSP plays a role in angular path integration, HD cells were monitored for $8 \mathrm{~min}$ in the cylinder with the cue card removed and the room lights turned off (Fig. 1A). We hypothesized that if RSP lesions weakened the processing of idiothetic information for angular path integration, the amount of preferred firing direction drift during darkness should be greater than that observed for control animals. Consistent with this hypothesis, the rate of mean preferred direction drift between $1 \mathrm{~min}$ epochs was greater for the RSP lesion groups in darkness with values ranging from 13.7 to $53.03^{\circ} / \mathrm{min}$ for lesioned rats, compared to 11.0 to $26.6^{\circ} / \mathrm{min}$ for the control group. Of the HD cells recorded in control animals, 6 of $17 \mathrm{HD}$ cells $(35.3 \%)$ drifted at a rate $>18 \% \mathrm{~min}$. However, this number was significantly lower when compared with the lesion group which had 11 of 15 cells $(73.3 \%)$ drifting at a rate $>18^{\circ} / \min \left(\chi^{2}(1)=4.01, p=0.045\right)$.

We also constructed HD versus time plots similar to those shown in Figure 4 for each cell monitored in the dark test, and then calculated the angular deviation of the HD values in each plot. On average, HD cells in RSP lesioned animals (electrolytic, $n=5$; neurotoxic, $n=10$ ) displayed greater HD variability in their preferred firing direction during the dark test (electrolytic, $43.4 \pm 5.69^{\circ}$; neurotoxic, $44.6 \pm 3.95^{\circ}$ ) compared with the control group $\left(31.4 \pm 2.70^{\circ}\right)$, suggesting that RSP lesions reduce directional stability in darkness. Because of the small number of HD cells recorded from electrolytic lesioned animals, and the absence of significant differences in angular deviation values between neurotoxic and electrolytic lesions $\left(t_{(13)}=-0.174 ; p=\right.$ $0.865)$, the two groups were pooled for statistical comparison
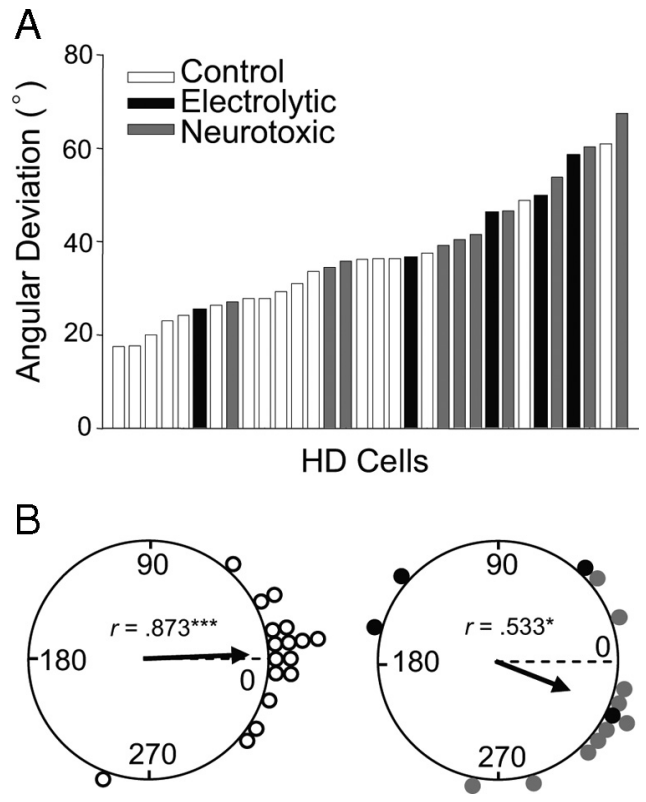

Figure 7. A, Plots showing the angular deviation of $H D$ values from each cell's corresponding HD versus time plot for the dark test. Plotted are the values for control (white bars), electrolytic RSP lesion (black bars), and neurotoxic RSP lesion (gray bars) groups during the 8 min dark session. Notice that angular deviation values are greater for the RSP lesion group. $\boldsymbol{B}$, Polar plots showing the angular shift in the preferred firing direction between the standard 2 and standard 3 sessions for control (left) and RSP lesioned (right) rats. Closed circles indicate the shift values for electrolytic lesioned animals, and the shaded circles represent the shift values from neurotoxic lesioned rats. Notice that the distribution of angular shift scores for the control and RSP lesion groups are distributed nonrandomly ( $\left.{ }^{*} p<0.05 ;{ }^{* * *} p<0.001\right)$.

with control animals. An independent sample $t$ test indicated that the amount of intrasession drift was significantly greater for the lesion group compared with the control group $\left(t_{(30)}=3.12 ; p=\right.$ $0.004)$. Figure $7 A$ shows a plot of the distribution of angular deviation values for each HD cell in controls and RSP lesion groups during the dark test. For the two cells from lesioned animals that had small angular deviation values, there was no noticeable difference between the extent of their lesions and lesions in other animals. Similarly, for the two cells in the lesioned group that had the largest drift in the dark, there were no obvious differences in the extent of their lesions from other animals. The absence of a significant relationship between lesion size and intrasession drift confirmed this observation (lesion size and angular deviation: $r=-0.169, p=0.547$; lesion size and $\% \mathrm{~min}: r=$ $0.019, p=0.945)$. Furthermore, the rats with large intrasession drift had a similar profile of impairments as other animals in the other experiments.

In summary, the results of the dark test show that RSP lesions reduce the ability of the $\mathrm{HD}$ cell circuit to use nonvisual cues to maintain directional orientation. Although this pattern of results may indicate an impairment in angular path integration, it is also possible that these differences were mediated by the presence of other nonvisual cues. For example, control animals may have used uncontrolled cues for stable orientation such as odor markings left on the enclosure floor or on the cylinder wall during the dark session (e.g., urine or boli). In contrast, because HD cells in the RSP lesioned group demonstrate weak landmark control, it is possible that lesioned animals could not accurately use such odor cues as landmarks, thus further reducing the stability of their preferred firing directions. To address this issue, a more rigorous test of angular path integration was conducted using the dualchamber apparatus (see section below). 


\section{Lights-on/landmark returned (standard 3)}

After the dark test, rats were returned to the cylinder enclosure for a final standard session (standard 3) in which they foraged for scattered food with the room lights turned back on and the cue card returned to its original location. The purpose of this final standard session was to determine whether HD preferred directions returned to their original orientation after drifting during the dark test. We therefore computed the amount of angular shift in HD cell preferred firing directions between the standard 2 and standard 3 sessions. Figure $7 B$ shows polar plots of these angular shift scores for control and RSP lesioned animals. The right plot indicates that some of the preferred firing directions of HD cells in RSP lesioned animals did not return to their original standard 2 orientation. On average, RSP lesioned rats had greater absolute shift values (45.6 \pm $\left.12.2^{\circ}\right)$ than those obtained from control rats $\left(19.8 \pm 6.30^{\circ}\right)$. This difference reached statistical significance as indicated by a $t$ test (because of the small number of HD cells recorded in electrolytic lesion animals, $n=4$, cells from both groups were pooled, total $n=14 ; t_{(19.7)}=2.46 ; p=$ $0.023)$. In contrast, a Rayleigh analysis revealed that angular shift values were nonrandomly distributed for the RSP lesion group ( $r=0.533 ; p<0.05$ ), with many of the shift values for the lesion group clustered around the zero mark in the polar plot, suggesting that the cue card had some control over HD cells in lesioned rats. This result is consistent with the results from the cue rotation experiments described above, in which the landmark cue had weak control over the cells' preferred directions.

\section{Dual-chamber test}

The dual-chamber test (Fig. $1 B$ ) requires the rat to walk from a familiar cylindrical environment through an unfamiliar passageway to a novel rectangular chamber. HD cells in control animals typically maintain a similar preferred firing direction between the cylinder and novel enclosures (Taube and Burton, 1995), and it has been shown that motor/proprioceptive cues available during the animal's journey through the passageway are necessary for maintaining a stable preferred direction (Stackman et al., 2003). A total of $10 \mathrm{HD}$ cells from control animals, 4 from electrolytic lesion rats, and 6 from neurotoxic lesion rats were tested in the dual-chamber. Because of the small number of electrolytic and neurotoxic lesion animals tested in the task, both lesion groups were pooled into one group.

Figure 8 displays firing rate versus HD plots for representative HD cells from control and RSP lesion animals (Fig. 8A) and polar plots of the angular shift between the cylinder and the rectangle for each cell in control animals (left) and the RSP lesioned (right) groups (Fig. 8B). Consistent with previous studies, HD cells in control animals maintained their orientation as the rats walked from the familiar cylinder to the novel rectangle (range $=-30^{\circ}$ to $\left.12^{\circ}\right)$. In contrast, some HD cells recorded in RSP lesioned rats showed instability when the animal locomoted from the cylinder
B
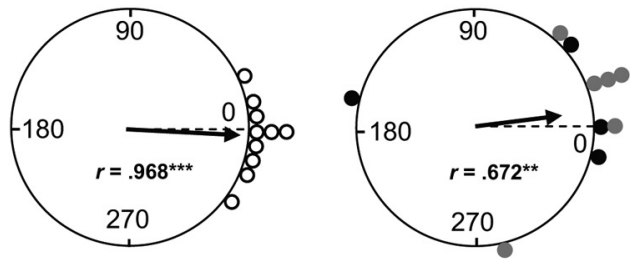

C
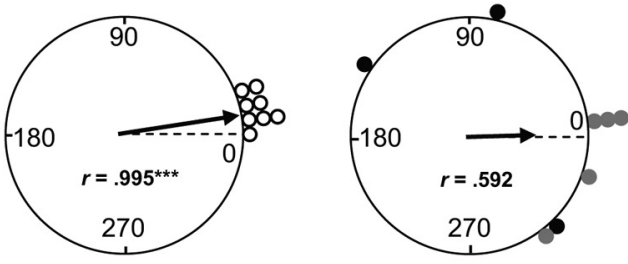

Figure 8. $\quad \boldsymbol{A}$, Representative firing rate versus HD tuning curves for HD cells from control (top) and RSP lesioned (bottom) 列

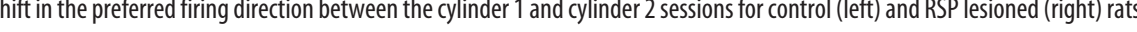
The shift scores for the RSP lesion group are distributed randomly as indicated by a nonsignificant Rayleigh test, suggesting that the cylinder cues exerted weak control over the cells' preferred firing direction.

to the rectangle. However, this instability was relatively mild in 8 of the 10 animals with angular shifts between the two chambers ranging from $-12^{\circ}$ to $42^{\circ}$. Indeed, an HD cell recorded in a rat with the largest RSP lesion (96\%) showed no preferred direction shift between the two chambers (angular shift $=0^{\circ}$ ), suggesting that this animal was capable of using idiothetic cues. Consistent with these observations, an independent sample $t$ test conducted on the absolute angular shift scores between the original cylinder and rectangle did not indicate significant group differences $\left(t_{(9.77)}\right.$ $=1.72, p=0.117)$, despite greater angular shift values for the RSP lesion group (RSP lesion, $39.0 \pm 16.1^{\circ}$; control, $10.8 \pm$ $3.32^{\circ}$ ). Moreover, a significant Rayleigh test indicated that the angular shift scores for the RSP lesion group were distributed nonrandomly ( $r=0.672 ; p=0.008)$, suggesting that the preferred directions of HD cells were largely maintained when entering the novel environment. Together, these findings indicate that the HD cell system is able to accurately integrate idiothetic information independently of the RSP.

Finally, to test whether the preferred directions of HD cells could return to their original orientation in the familiar cylinder, animals were allowed to walk back from the novel rectangle to the familiar cylindrical enclosure (Fig. $1 C$ ). Figure $8 C$ shows the angular shift scores between the original cylinder (cylinder 1) and return cylinder (cylinder 2) sessions for cells in RSP (Fig. 8C, right) lesioned and control groups (Fig. $8 C$, left). On average, absolute angular shift values were greater for the RSP lesion groups $\left(43.5 \pm 16.4^{\circ}\right)$ compared with control animals $(9.75 \pm$ $\left.2.25^{\circ}\right)$, and this difference approached, but did not reach significance $\left(t_{(7.26)}=2.04, p=0.08\right)$. A Rayleigh test conducted on the angular shift scores for RSP lesions indicated that the distribution 
was random, however, the test again only approached significance $(r=0.592 ; p=0.058)$. It is noteworthy that the rat that showed no preferred direction shift between the cylinder and rectangle displayed a large directional shift when returning to the cylinder $\left(138^{\circ}\right)$. This example, along with the results above, indicates that the familiar landmark had weak control over the preferred directions of HD cells in RSP lesioned animals, and is again consistent with the weak cue control found in the cue rotation and the lights on/landmark return experiments.

\section{Discussion}

The present study aimed to determine whether the RSP plays a role in processing the HD cell signal. We first showed that lesions of the RSP reduced the directional specificity of ADN HD cells, and increased the time by which they anticipate future heading. We also show that RSP lesions weaken landmark control over HD cells. For example, the preferred directions of HD cells in RSP lesioned animals (1) drifted considerably, even in the light (Fig. $4 B, C)$; (2) failed to maintain orientation in relation to the cue card when it was rotated $90^{\circ}$, or when it was returned to its original position (Figs. $6 \mathrm{~B}, \mathrm{C}, 7 \mathrm{~B}$ ); and (3) failed to return to their original orientation when the animal returned to the cylinder in the dual-chamber test (Fig. $8 C$ ). Together, these results indicate that the RSP plays an important role in processing the ADN HD cell signal, and specifically suggests that the RSP is involved in integrating visual information into the HD cell circuit.

\section{Retrosplenial cortex lesions and visual landmark control of head direction cells}

The finding that lesions of the RSP weakened visual landmark control of ADN HD cells is consistent with previous behavioral studies showing impairments in visually guided navigation after RSP damage in human patients and after selective lesions in rats (Sutherland et al., 1988; Harker and Whishaw, 2002, 2004; Vann and Aggleton, 2004, 2005; Cain et al., 2006; Epstein, 2008). As discussed earlier, damage of the RSP after stroke in humans produces a form of topographical disorientation termed heading disorientation - an inability to determine the direction of orientation with respect to environmental landmarks (Aguirre and D'Esposito, 1999; Maguire, 2001). Interestingly, these impairments do not include disturbances in recognizing environmental landmarks, an ability attributed to the parahippocampal place area in the human temporal lobe (Epstein and Kanwisher, 1998, Epstein et al., 1999). Instead, the impairments appear to be specific to deriving directional information from landmarks. Anatomically, the RSP is in a pivotal position to construct associations between visual stimuli and the HD cell system because it receives direct inputs from visual processing areas such as areas $17,18 \mathrm{~b}$, and the lateral dorsal thalamus (van Groen and Wyss, 1990, 1992, 2003), and it receives strong inputs from HD cellcontaining regions such as the ADN and PoS (Fig. 9). Information about the animal's HD in relation to visual landmarks is likely conveyed to the ADN through three possible routes: (1) direct projections from the RSP (van Groen and Wyss, 1992), (2) through its reciprocal connections with the PoS (Wyss and Van Groen, 1992; Jones and Witter, 2007), or (3) through projections from the lateral mammillary nucleus via its connections with the PoS (Allen and Hopkins, 1989; Hayakawa and Zyo, 1989; Shibata, 1989).

Although the results of the present study demonstrate that the RSP is involved in associating the HD cell signal with salient visual landmarks, prior work has shown that landmark control of HD cells also requires an intact PoS (Goodridge and Taube, 1997;

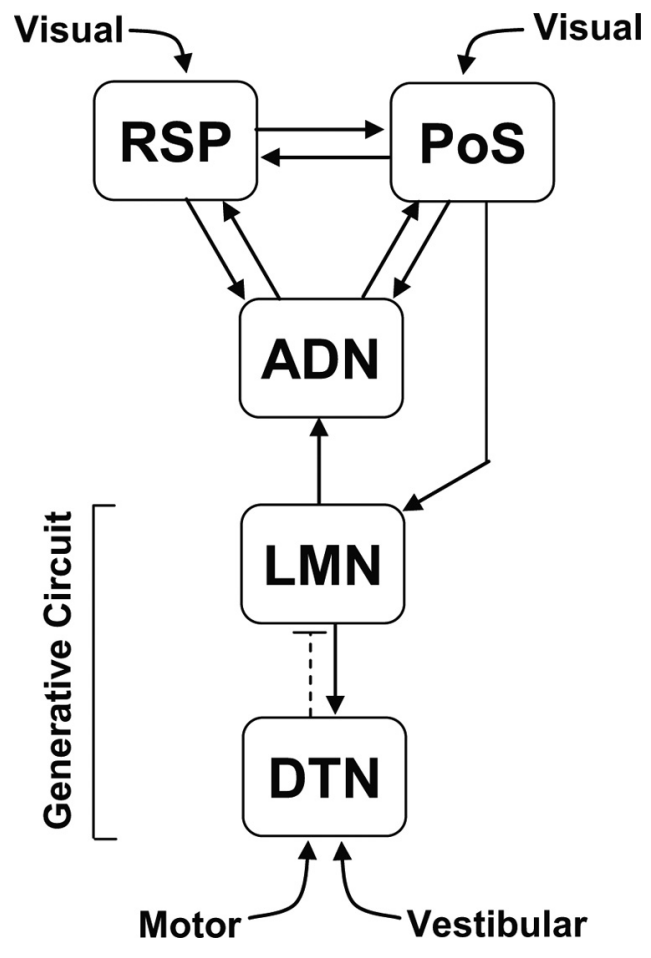

Figure 9. A working model of information flow in the HD cell circuit. Dark arrows represent excitatory connections, whereas broken lines depict inhibitory connections. The DTN and LMN receive direct inputs from brain regions conveying self-movement information (vestibular and motor) about angular head movements (Brown et al., 2005; Biazoli et al., 2006; Clark et al., 2009). Thus, it has been hypothesized that the origins of the HD signal reside within the connections between the DTN and LMN (Taube, 2007). Previous work suggests that the projections from the POS to the ADN and LMN constitute a pathway in which visual information enters the HD cell circuit (Goodridge and Taube, 1997; Yoder and Taube, 2008). The results of the present study extend the model to include the RSP in the processing of visual information for landmark control of HD cells. Information from the RSP may be integrated into the HD circuit via its reciprocal connections with the PoS and/or the ADN.

Yoder and Taube, 2008). It is also important to note that the loss of landmark control over HD cells is generally milder after RSP lesions compared with PoS lesions (Goodridge and Taube, 1997; Yoder and Taube, 2008). For instance, in the present study, cells in RSP lesioned rats rotated in the expected direction more frequently (19 of 26 sessions: $73 \%$ ) compared with cue control in PoS lesioned animals (27 of 61 sessions: $44 \%$ ). Furthermore, HD cells in neurotoxic RSP lesioned rats showed lower mean absolute shift values in the cue rotation sessions (standard 1 to standard 2: $29.6 \pm 8.24^{\circ}$ ) than those observed in PoS lesioned rats (standard 1 to standard 2: $65.6 \pm 10.6^{\circ}$ ). The PoS has both direct and extensive connections with visual processing regions such as areas 17, 18b, and the lateral dorsal thalamus (Vogt and Miller, 1983; van Groen and Wyss, 1990, 1992, 2003). Thus, it is possible that the direct visual inputs to the PoS provide key information in the absence of the RSP. Nevertheless, RSP lesions did produce significant impairments in landmark control relative to control animals, suggesting that the pathway conveying visual information through the PoS does not completely compensate in the absence of the RSP. Surprisingly, RSP connections with the parietal cortex do not appear to play a critical role in landmark control as lesions of the parietal cortex do not disrupt cue card control of ADN HD cells (Calton et al., 2008). Thus, RSP's role in processing landmark information appears to be independent of its connections with parietal cortex.

In contrast to a role in integrating visual information into the HD cell circuit, it is important to address the possibility that the 
deficits in landmark control relate to a general deficiency in switching to a landmark-based frame from some other source of information (e.g., path integration-based) (Vann et al., 2009). Consistent with this possibility, behavioral studies have shown that changes in the demands of spatial tasks frequently impair accurate performance by RSP lesioned animals, suggesting that RSP lesioned animals have difficulty switching between different spatial strategies (Vann and Aggleton, 2005). Computational models have also been developed in which the RSP plays a fundamental role in switching between spatial viewpoints, for instance, aiding in the switch between viewer-dependent and viewer-independent reference frames and vice versa (Burgess, 2008). Thus, whether the RSP helps switch the HD cell system between spatial codes should be addressed systematically in future work.

\section{Retrosplenial cortex lesions and path integration}

Two tests were conducted to determine whether ADN HD cells were capable of maintaining their orientation in the absence of familiar visual cues, which likely involves the integration of idiothetic information, or angular path integration. In the first test, HD cells were monitored under darkened conditions, in which the familiar cue card was removed and the room lights were turned off. Although under these conditions the preferred firing directions of HD cells in lesioned rats showed significantly greater drift than control animals, it was possible that other sources of information may have contributed to the differences. For example, control animals may have used uncontrolled odor landmarks (e.g., urine or boli) to maintain orientation while foraging in darkness. Thus, to further evaluate the path integration abilities of ADN HD cells, animals were tested in the dualchamber apparatus, which required the animal to walk from a familiar environment to a novel one (Taube and Burton, 1995). For control animals, HD cells maintained their orientation when animals walked from the familiar cylinder to the novel rectangle, presumably because they integrated information about their own movements (Stackman et al., 2003). Similarly, the preferred directions of HD cells in RSP lesioned rats were largely maintained between the two enclosures, suggesting that the RSP does not make an important contribution to the path integration-based stability of HD cell preferred directions.

These results are consistent with current theories suggesting that the HD signal is generated and maintained by path integration primarily within subcortical circuitry (Fig. 9). Evidence suggests that the origin of the HD cell signal resides within the reciprocal connections of the dorsal tegmental nucleus (DTN) and lateral mammillary nucleus (LMN) because bilateral lesions to either structure completely abolishes the HD signal within the ADN (Blair et al., 1999; Bassett et al., 2007), and because both structures contain cells that are responsive to the animals angular head velocity, a source of self-movement information that can be integrated over time to determine an animals current HD (Stackman and Taube, 1998; Blair et al., 1999; Bassett and Taube, 2001; Sharp et al., 2001). Anatomical and physiological evidence suggests that angular head velocity signals are directly conveyed through pathways stemming from the vestibular nuclei in the brainstem to the DTN and LMN (Brown et al., 2005; Biazoli et al., 2006). Angular head velocity information may also be conveyed to the DTN through motor pathways extending from the striatum to the lateral habenula and interpeduncular nucleus (Sharp et al., 2006; Clark et al., 2009).

Although our data suggest that the RSP does not play a central role in directional or angular path integration, the results do not preclude the possibility that the RSP is involved in path integrating an animal's current location in an environment. Specifically, the RSP may be a component of a distributed circuit that integrates a highly processed HD signal with information about the distance or time traveled relative to a reference point or home base. A role for the RSP in positional path integration is consistent with experiments that have identified a small population of RSP neurons with combined HD and place correlates (Cho and Sharp, 2001). These conjunctive neural signals may constitute a prerequisite for the formation of path integration-based spatial representations within closely interconnected hippocampal regions (McNaughton et al., 2006; Sargolini et al., 2006). Indeed, temporary inactivation of the RSP disrupts location-specific place cell activity in the hippocampus (Cooper and Mizumori, 2001), especially under darkened conditions, in which path integration is likely used.

In conclusion, the present study demonstrates an essential role for the RSP in processing the ADN HD representation, and suggests that the RSP is involved in linking the HD cell system with environmental landmarks. Having established a functional relationship between the RSP and HD signal, subsequent studies may attempt to assess the interactions between the RSP and other brain regions involved in processing spatial representations (Moser et al., 2008).

\section{References}

Aggleton JP, Vann SD (2004) Testing the importance of the retrosplenial navigation system: lesion size but not strain matters: a reply to Harker and Whishaw. Neurosci Biobehav Rev 28:525-531.

Aggleton JP, Neave N, Nagle S, Sahgal A (1995) A comparison of the effects of medial prefrontal, cingulate cortex, and cingulum bundle lesions on tests of spatial memory: evidence of a double dissociation between frontal and cingulum bundle contributions. J Neurosci 15:7270-7281.

Aguirre GK, D’Esposito M (1999) Topographical disorientation: a synthesis and taxonomy. Brain 122:1613-1628.

Allen GV, Hopkins DA (1989) Mammillary body in the rat: topography and synaptology of projections from the subicular complex, prefrontal cortex, and midbrain tegmentum. J Comp Neurol 286:311-336.

Bassett JP, Taube JS (2001) Neural correlates for angular head velocity in the rat dorsal tegmental nucleus. J Neurosci 21:5740-5751.

Bassett JP, Tullman ML, Taube JS (2007) Lesions of the tegmentomammillary circuit in the head direction system disrupts the head direction signal in the anterior thalamus. J Neurosci 27:7564-7577.

Batschelet E (1981) Circular statistics in biology. New York: Academic.

Biazoli CE Jr, Goto M, Campos AM, Canteras NS (2006) The supragenual nucleus: a putative relay station for ascending vestibular signs to head direction cells. Brain Res 1094:138-148.

Blair HT, Sharp PE (1995) Anticipatory head direction signals in anterior thalamus: evidence for a thalamocortical circuit that integrates angular head motion to compute head direction. J Neurosci 15:6260-6270.

Blair HT, Lipscomb BW, Sharp PE (1997) Anticipatory time intervals of head-direction cells in the anterior thalamus of the rat: implications for path integration in the head-direction circuit. J Neurophysiol 78:145-159.

Blair HT, Cho J, Sharp PE (1998) Role of the lateral mammillary nucleus in the rat head direction circuit: a combined single-unit recording and lesion study. Neuron 21:1387-1397.

Blair HT, Cho J, Sharp PE (1999) The anterior thalamic head-direction signal is abolished by bilateral but not unilateral lesions of the lateral mammillary nucleus. J Neurosci 19:6673-6683.

Brown JE, Card JP, Yates BJ (2005) Polysynaptic pathways from the vestibular nuclei to the lateral mammillary nucleus of the rat: substrates for vestibular input to head direction cells. Exp Brain Res 161:47-61.

Burgess N (2008) Spatial cognition and the brain. Ann N Y Acad Sci 1124:77-97.

Cain DP, Humpartzoomian R, Boon F (2006) Retrosplenial cortex lesions impair water maze strategies learning or spatial place learning depending on prior experience of the rat. Behav Brain Res 170:316-325.

Calton JL, Turner CS, Cyrenne DL, Lee BR, Taube JS (2008) Landmark 
control and updating of self-movement cues are largely maintained in head direction cells after lesions of the posterior parietal cortex. Behav Neurosci 122:827-840.

Cammalleri R, Gangitano M, D’Amelio M, Raieli V, Raimondo D, Camarda R (1996) Transient topographic amnesia and cingulated cortex damage: a case report. Neuropsychologia 34:321-326.

Chen LL, Lin LH, Green EJ, Barnes CA, McNaughton BL (1994) Headdirection cells in the rat posterior cortex. I. Anatomical distribution and behavioral modulation. Exp Brain Res 101:8-23.

Cho J, Sharp PE (2001) Head direction, place, and movement correlates for cells in the rat retrosplenial cortex. Behav Neurosci 115:3-25.

Clark BJ, Sarma A, Taube JS (2009) Head direction cell instability in the anterior dorsal thalamus after lesions of the interpeduncular nucleus. J Neurosci 29:493-507.

Cooper BG, Mizumori SJ (1999) Retrosplenial cortex inactivation selectively impairs navigation in darkness. Neuroreport 10:625-630.

Cooper BG, Mizumori SJ (2001) Temporary inactivation of the retrosplenial cortex causes a transient reorganization of spatial coding in the hippocampus. J Neurosci 21:3986-4001.

Cooper BG, Manka TF, Mizumori SJ (2001) Finding your way in the dark: the retrosplenial cortex contributes to spatial memory and navigation without visual cues. Behav Neurosci 115:1012-1028.

Dean HL, Platt ML (2006) Allocentric spatial referencing of neuronal activity in macaque posterior cingulate cortex. J Neurosci 26:1117-1127.

Domesick VB (1970) The fasciculus cinguli in the rat. Brain Res 20:19-32.

Epstein R, Kanwisher N (1998) A cortical representation of the local visual environment. Nature 392:598-601.

Epstein R, Harris A, Stanley D, Kanwisher N (1999) The parahippocampal place area: recognition, navigation, or encoding? Neuron 23:115-125.

Epstein RA (2008) Parahippocampal and retrosplenial contributions to human spatial navigation. Trends Cogn Sci 12:388-396.

Epstein RA, Parker WE, Feiler AM (2007) Where am I now? Distinct roles for parahippocampal and retrosplenial cortices in place recognition. J Neurosci 27:6141-6149.

Golob EJ, Taube JS (1999) Head direction cells in rats with hippocampal or overlying neocortical lesions: evidence for impaired angular path integration. J Neurosci 19:7198-7211.

Goodridge JP, Taube JS (1997) Interaction between postsubiculum and anterior thalamus in the generation of head direction cell activity. J Neurosci 17:9315-9330.

Goodridge JP, Dudchenko PA, Worboys KA, Golob EJ, Taube JS (1998) Cue control and head direction cells. Behav Neurosci 112:749-761.

Greene KK, Donders J, Thoits T (2006) Topographical heading disorientation: a case study. Appl Neuropsychol 13:269-274.

Harker KT, Whishaw IQ (2002) Impaired spatial performance in rats with retrosplenial lesions: importance of the spatial problem and the rat strain in identifying lesion effects in a swimming pool. J Neurosci 22:1155-1164.

Harker KT, Whishaw IQ (2004) A reaffirmation of the retrosplenial contribution to rodent navigation: reviewing the influences of lesion, strain, and task. Neurosci Biobehav Rev 28:485-496.

Hayakawa T, Zyo K (1989) Retrograde double-labeling study of the mammillothalamic and the mammillotegmental projections in the rat. J Comp Neurol 284:1-11.

Iaria G, Chen JK, Guariglia C, Ptito A, Petrides M (2007) Retrosplenial and hippocampal brain regions in human navigation: complementary functional contributions to the formation and use of cognitive maps. Eur J Neurosci 25:890-899.

Ino T, Doi T, Hirose S, Kimura T, Ito J, Fukuyama H (2007) Directional disorientation following left retrosplenial hemorrhage: a case report with fMRI studies. Cortex 43:248-254.

Jarrard LE (1989) On the use of ibotenic acid to lesion selectively different components of the hippocampal formation. J Neurosci Methods 29:251-259.

Jones BF, Witter MP (2007) Cingulate cortex projections to the parahippocampal region and hippocampal formation in the rat. Hippocampus 17:957-976.

Kubie JL (1984) A driveable bundle of microwires for collecting single-unit data from freely-moving rats. Physiol Behav 32:115-118.

Lukoyanov NV, Lukoyanova EA, Andrade JP, Paula-Barbosa MM (2005) Impaired water maze navigation of Wistar rats with retrosplenial cortex lesions: effect of nonspatial pretraining. Behav Brain Res 158:175-182.
Maguire EA (2001) The retrosplenial contribution to human navigation: a review of lesion and neuroimaging findings. Scand J Psychol 42:225-238.

McNaughton BL, Battaglia FP, Jensen O, Moser EI, Moser MB (2006) Path integration and the neural basis of the 'cognitive map.' Nat Rev Neurosci 7:663-678.

Moser EI, Kropff E, Moser MB (2008) Place cells, grid cells, and the brain's spatial representation system. Annu Rev Neurosci 31:69-89.

Muir GM, Brown JE, Carey JP, Hirvonen TP, Della Santina CC, Minor LB, Taube JS (2009) Disruption of the head direction cell signal after occlusion of the semicircular canals in the freely moving chinchilla. J Neurosci 29:14521-14533.

Neave N, Nagle S, Sahgal A, Aggleton JP (1996) The effects of discrete cingulum bundle lesions in the rat on the acquisition and performance of two tests of spatial working memory. Behav Brain Res 80:75-85.

Neitz J, Jacobs GH (1986) Reexamination of spectral mechanisms in the rat (Rattus norvegicus). J Comp Psychol 100:21-29.

Osawa A, Maeshima S, Kunishio K (2008) Topographic disorientation and amnesia due to cerebral hemorrhage in the left retrosplenial region. Eur Neurol 59:79-82.

Park S, Chun MM (2009) Different roles for the parahippocampal place area (PPA) and retrosplenial cortex (RSC) in panoramic scene perception. Neuroimage 47:1747-1756.

Paxinos G, Watson C (1998) The rat brain in stereotaxic coordinates, Ed 4. San Diego: Academic.

Pothuizen HH, Aggleton JP, Vann SD (2008) Do rats with retrosplenial cortex lesions lack direction? Eur J Neurosci 28:2486-2498.

Sargolini F, Fyhn M, Hafting T, McNaughton BL, Witter MP, Moser MB, Moser EI (2006) Conjunctive representation of position, direction, and velocity in entorhinal cortex. Science 312:758-762.

Sharp PE, Tinkelman A, Cho J (2001) Angular velocity and head direction signals recorded from the dorsal tegmental nucleus of Gudden in the rat: implications for path integration in the head direction cell circuit. Behav Neurosci 115:571-588.

Sharp PE, Turner-Williams S, Tuttle S (2006) Movement related correlates of single cell activity in the interpeduncular nucleus and habenula of the rat during a pellet-chasing task. Behav Brain Res 166:55-70.

Shibata H (1989) Descending projections to the mammillary nuclei in the rat, as studied by retrograde and anterograde transport of wheat germ agglutinin-horseradish peroxidase. J Comp Neurol 285:436-452.

Shibata H, Honda Y, Sasaki H, Naito J (2009) Organization of intrinsic connections of the retrosplenial cortex in the rat. Anat Sci Int 84:280-292.

Stackman RW, Taube JS (1998) Firing properties of rat lateral mammillary single units: head direction, head pitch, and angular head velocity. J Neurosci 18:9020-9037.

Stackman RW, Golob EJ, Bassett JP, Taube JS (2003) Passive transport disrupts directional path integration by rat head direction cells. J Neurophysiol 90:2862-2874.

Sutherland RJ, Whishaw IQ, Kolb B (1988) Contributions of cingulate cortex to two forms of spatial learning and memory. J Neurosci 8:1863-1872.

Swanson LW (1992) Brains maps: structure of the rat brain. New York: Elsevier.

Tabachnick BG, Fidell LS (2007) Using multivariate statistics, Ed 5. Boston: Allyn and Bacon.

Takahashi N, Kawamura M, Shiota J, Kasahata N, Hirayama K (1997) Pure topographic disorientation due to right retrosplenial lesion. Neurology 49:464-469.

Taube JS (1995) Head direction cells recorded in the anterior thalamic nuclei of freely moving rats. J Neurosci 15:70-86.

Taube JS (2007) The head direction signal: origins and sensory-motor integration. Annu Rev Neurosci 30:181-207.

Taube JS, Burton HL (1995) Head direction cell activity monitored in a novel environment and during a cue conflict situation. J Neurophysiol 74:1953-1971.

Taube JS, Muller RU (1998) Comparisons of head direction cell activity in the postsubiculum and anterior thalamus of freely moving rats. Hippocampus 8:87-108.

Taube JS, Muller RU, Ranck JB Jr (1990a) Head-direction cells recorded from the postsubiculum in freely moving rats. I. Description and quantitative analysis. J Neurosci 10:420-435.

Taube JS, Muller RU, Ranck JB Jr (1990b) Head-direction cells recorded from the postsubiculum in freely moving rats. II. Effects of environmental manipulations. J Neurosci 10:436-447. 
van Groen T, Wyss JM (1990) Connections of the retrosplenial granular a cortex in the rat. J Comp Neurol 300:593-606.

van Groen T, Wyss JM (1992) Connections of the retrosplenial dysgranular cortex in the rat. J Comp Neurol 315:200-216.

van Groen T, Wyss JM (2003) Connections of the retrosplenial granular b cortex in the rat. J Comp Neurol 463:249-263.

Vann SD, Aggleton JP (2002) Extensive cytotoxic lesions of the rat retrosplenial cortex reveal consistent deficits on tasks that tax allocentric spatial memory. Behav Neurosci 116:85-94.

Vann SD, Aggleton JP (2004) Testing the importance of the retrosplenial guidance system: effects of different sized retrosplenial cortex lesions on heading direction and spatial working memory. Behav Brain Res 155:97-108.

Vann SD, Aggleton JP (2005) Selective dysgranular retrosplenial cortex lesions in rats disrupt allocentric performance of the radial-arm maze task. Behav Neurosci 119:1682-1686.

Vann SD, Kristina Wilton LA, Muir JL, Aggleton JP (2003) Testing the importance of the caudal retrosplenial cortex for spatial memory in rats. Behav Brain Res 140:107-118.

Vann SD, Aggleton JP, Maguire EA (2009) What does the retrosplenial cortex do? Nat Rev Neurosci 10:792-802.

Vogt BA, Miller MW (1983) Cortical connections between rat cingulate cortex and visual, motor, and postsubicular cortices. J Comp Neurol 216:192-210.

Warburton EC, Aggleton JP, Muir JL (1998) Comparing the effects of selec- tive cingulate cortex lesions and cingulum bundle lesions on water maze performance by rats. Eur J Neurosci 10:622-634.

Wesierska M, Adamska I, Malinowska M (2009) Retrosplenial cortex lesion affected segregation of spatial information in place avoidance task in the rat. Neurobiol Learn Mem 91:41-49.

Whishaw IQ, Maaswinkel H, Gonzalez CL, Kolb B (2001) Deficits in allothetic and idiothetic spatial behavior in rats with posterior cingulate cortex lesions. Behav Brain Res 118:67-76.

Wiener SI, Taube JS (2005) Head direction cells and the neural mechanisms of spatial orientation. Cambridge, MA: MIT.

Wolbers T, Büchel C (2005) Dissociable retrosplenial and hippocampal contributions to successful formation of survey representations. J Neurosci 25:3333-3340.

Wyss JM, Sripanidkulchai K (1984) The topography of the mesencephalic and pontine projections from the cingulate cortex of the rat. Brain Res 293:1-15.

Wyss JM, Van Groen T (1992) Connections between the retrosplenial cortex and the hippocampal formation in the rat: a review. Hippocampus 2:1-11.

Yoder R, Taube JS (2008) The postsubiculum provides visual landmark control to the head direction signal at the lateral mammillary nuclei. Program no. 90.9. 2008 Neuroscience Meeting Planner. Washington, DC: Society for Neuroscience. Online.

Yoder RM, Taube JS (2009) Head direction cell activity in mice: robust directional signal depends on intact otolith organs. J Neurosci 29:1061-1076. 